DOI: $10.5604 / 01.3001 .0012 .8023$

\title{
OVERVIEW OF APPLICATIONS OF WIRE MEDIUM IN RADIO ENGINEERING MEANS
}

\author{
Mykola Khobzei $^{1}$, Dmytro Vovchuk ${ }^{1}$, Magdalena Michalska ${ }^{2}$ \\ ${ }^{1}$ Yuriy Fedkovych Chernivtsi National University, Department of Radio Engineering and Information Security \\ ${ }^{2}$ Lublin University of Technology, Institute of Electronics \& Information Technology, Lublin, Poland
}

\begin{abstract}
This paper presents an overview of the main possible applications of wire medium in different field of radio engineering. Wire media possesses the unique electromagnetic properties. There is a number for approaches for manufacturing the wire media of different shapes from microwave frequency up to optical one. The wire media that consists of parallel metallic rods finds application for narrow and broadband power radiation in photovoltaic devices, imaging, endoscopy and many others. The wire metastructures such as hyperlens and brush are applicable to the antennas of wide frequency range.
\end{abstract}

Keywords: wire media, superlens, hyperlens, brush, metamaterial

\section{PRZEGLĄD ZASTOSOWAŃ KONSTRUKCJI Z PRZEWODÓW W URZĄDZENIACH RADIOWYCH}

Streszczenie. W niniejszej pracy dokonano przegląu głównych możliwych zastosowań struktur z przewodów w różnych dziedzinach inżynierii radiowej. Struktury z przewodów posiadaja unikalne właściwości. Istnieje wiele podejść do wytwarzania struktur o różnych kształtach $i$ zastosowaniach od zakresu czestotliwości mikrofalowych do optycznych. Struktury składajace sie z równoległych przewodników sq wykorzystywane do transmisji fal waskopasmowych $i$ szerokopasmowych fal elektromagnetycznych w urządzeniach fotowoltaicznych, transferu obrazów, endoskopii $i$ wielu innych. Konstrukcje z przewodów, takie jak hiperłacza oraz z losowym rozmieszczeniem przewodów, moga być wykorzystywane do projektowania anten działajacych w szerokim zakresie częstotliwości.

Słowa kluczowe: struktury z przewodów, supersoczewka, hipersoczewka, struktura z losowym rozmieszczeniem przewodów, metamateriały

\section{Introduction}

Metamaterials is the class of artificial materials with the negative values of permittivity and/or permeability that cannot be found in nature $[6,13]$. Such effect is explained by purely internal characteristics that can depend on the dimensions of metamaterial elements, their shape, distances between them and others.

Wire media is a unique class of metamaterials that can be simply manufactured for the wide frequency range from radio and microwave frequencies up to optical and higher [14]. It is possible due to the number of approaches for production of WM of different dimensions that include mechanical assembling of metallic wires into arrays and fabrication of micro- and nanostructured WM which operate in $\mathrm{THz}$, IR and visible frequencies. Some of such technologies are anodic electrochemical etching, anodization of aluminum and influence of ion beam on track membranes of different dielectrics. As a result, there is a possibility to manufacture the porous matrixes with thickness up to $2 \mu \mathrm{m}$ and diameter of pore $20 \mathrm{~nm}[2,7,17]$. It became the reason of intensive studying WM. There are many works where such metamaterials are presented with different shapes $[1,6,14]$. The most popular of them (superlens, hyperlens and brush) and their applications are considered in this chapter based on the last scientific investigations. Therefore, goal of the paper is an overview of modern applications of WM for different radio engineering devices and telecommunication means as well as discussion of further possible usage of such metamaterial.

\section{Parallel Metallic Wire Structure}

The structure that consists of arranged parallel metallic wires with the finite values of wires length $L$, their diameter $2 r$ and lattice period $a$ included into dielectric matrix is called superlens (Fig. 1 - CST model and experimental sample) and finds the number of applications [3, 14, 19].

First of all, WM is known as a mean of imaging. As is shown in earl works it is possible at Fabri-Perot resonances of WM in different frequency ranges $[4,5]$. One of examples is depicted in Fig. 2 [5]. An antenna that has shape of the wished picture is located in front of the structure in the distance not more than the value of lattice period of WM. There were two experiments for both 894 and $1034 \mathrm{MHz}$. As one can see from comparison of electric field distributions at the back side of WM (Fig. $2 b-$ right top and bottom), such device can operate only at Fabry-Perot resonance and the right bottom picture is vague.

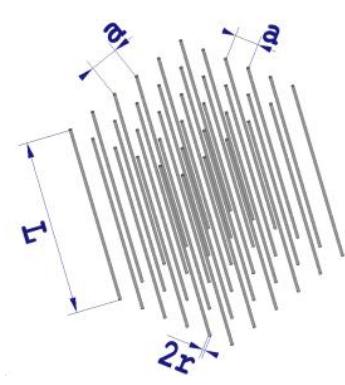

a)

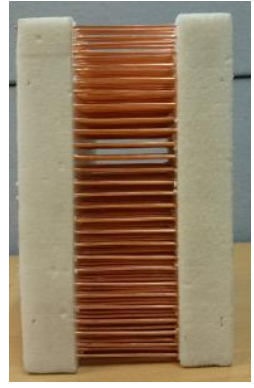

b)
Fig. 1. Wire media that consists of parallel metallic wires with length $L$, diameter $2 r$ and lattice period a: CST model (a) and experimental sample (b) [19]

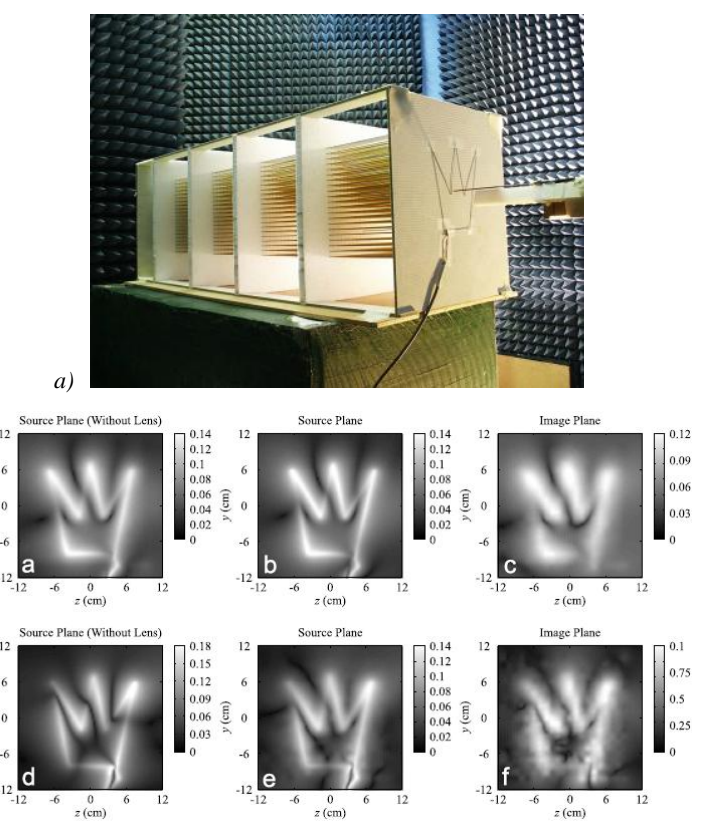

Fig. 2. Wire media of microwave frequency range (a) that can transfer images at Fabri-Perot resonance (b) [4] 
There was a restriction within the previously described approach for EM wave transfer because such application of WM is limited by general dimensions of the structure. The first idea of broadband power transfer was proposed in [11] as an effective WM multilayer between the emitter and photovoltaic cell as shown in Fig. 3. The experimental investigation as a proof of broadband power transfer was carried out in [19] where waveguide ports were placed one in front of another by their apertures in some distance. The air gap between ports was filled out by parallel metallic slab that allows enhancing transmission of EM power in a few times in comparison with the case when the transmission through the free space [10,19]. Those studies opened new possibilities of WM in a number of applications including control radiative heat flows in thermophotovoltaic devices, sensing, effective multimode telecommunications and others.
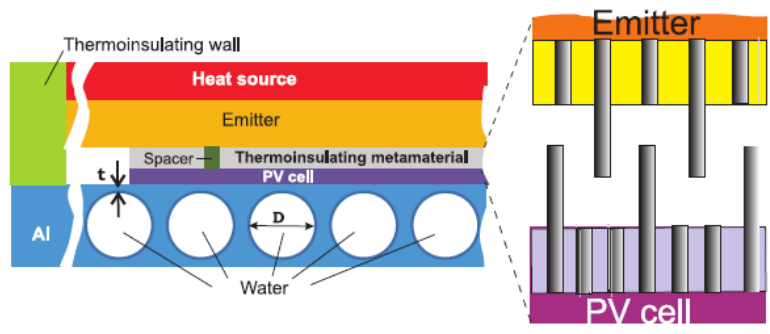

Fig. 3. A micro-gap thermophotovoltaic system enhanced by metamaterial with parallel metallic wires [11]

The broadband effect of power transfer became an initial point for the development of the means for endoscopy. In [16, 20] the WM that consists on parallel wires is base for the suggested device. The endoscope contains WM included into the porous polyethylene matrix that can operate in microwave and $\mathrm{THz}$ frequency ranges. The investigation in $[16,20]$ shows that the endoscope keeps its transmission properties under the bending with different values of angle even more than $180^{\circ}$ for the optically long structure $2 \mathrm{~cm}$ for the frequency range $0.5 \div 1 \mathrm{THz}$ (for the bending radius $\mathrm{R}$ approx. $6.3 \mathrm{~mm}$ ). Moreover, such device demonstrates functionality when it is folded with radius $\mathrm{R} \approx \lambda$ at the frequencies below $0.75 \mathrm{THz}$ [20].
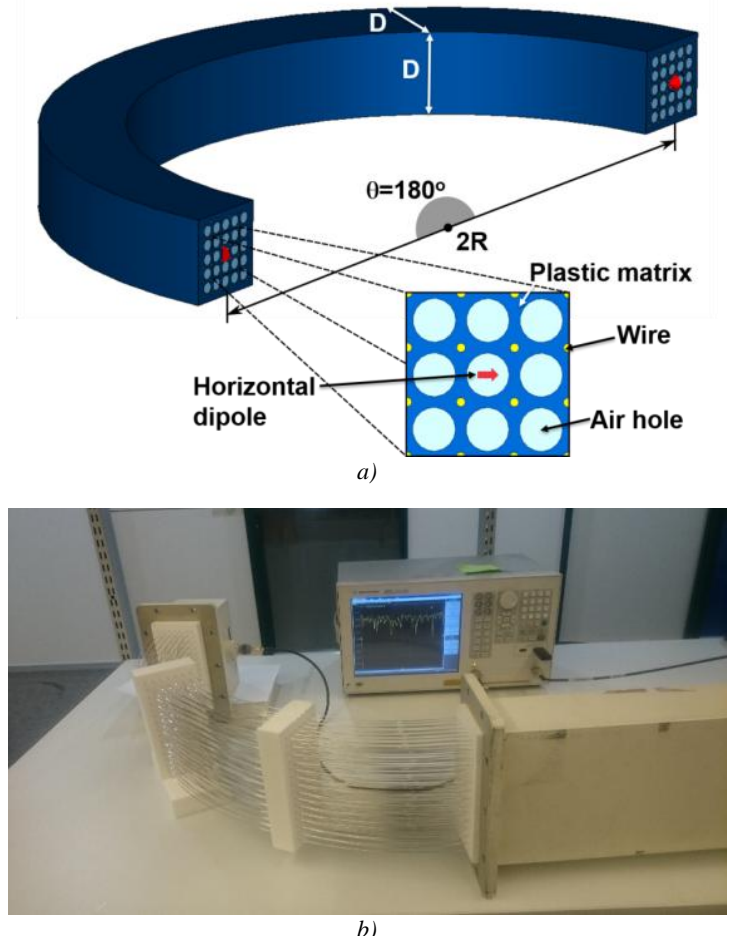

Fig. 4. A model of THz endoscope that consists of parallel metallic wires included into porous dielectric matrix (a) and its microwave experimental setup (b) [16, 20]
The experimental investigation of the suggested WM endoscope in microwave range has confirmed its stable work for the bending with different angles that were equal $90^{\circ}, 180^{\circ}$ and more. The calculated loss dispersion for the straight and bent endoscope is shown in Fig. 5 [20]. The averaged values $\langle\mathrm{P}\rangle$ are $0.38,0.4$ and 0.41 that correspond on the different angles demonstrate the effectiveness and the huge role of $\mathrm{WM}$ in this scientific field.

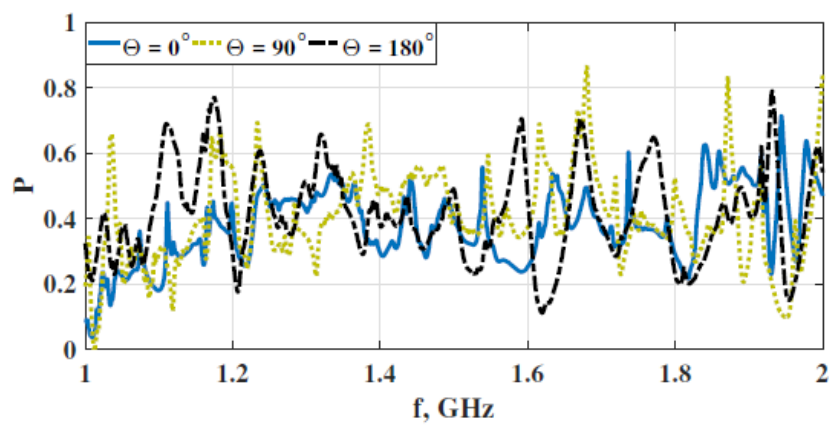

Fig. 5. Dispersion of power loss for straight endoscope as well as the bent on with angles 90 and $180^{\circ}$ that obtained by the microwave experiment [20]

\section{Tapered Wire Media}

The WM structure that consists of array of tapered metallic wires, so-called hyperlens, was suggested to solve a problem of enhancement of propagation EM modes. In Fig. 6 the hyperlens was considered as a structure that allows to fix the noise oscillations and enhance the power of very weak radiation [9]. It is possible due to the shape of suggested structure because the input and output aperture are different and the enhancement factor depends on the relation of their dimensions.

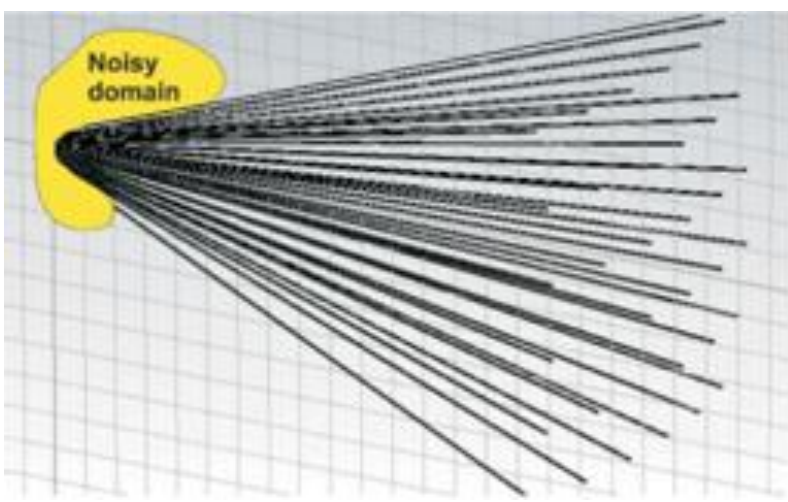

Fig. 6. A model of tapered metamaterial [9]

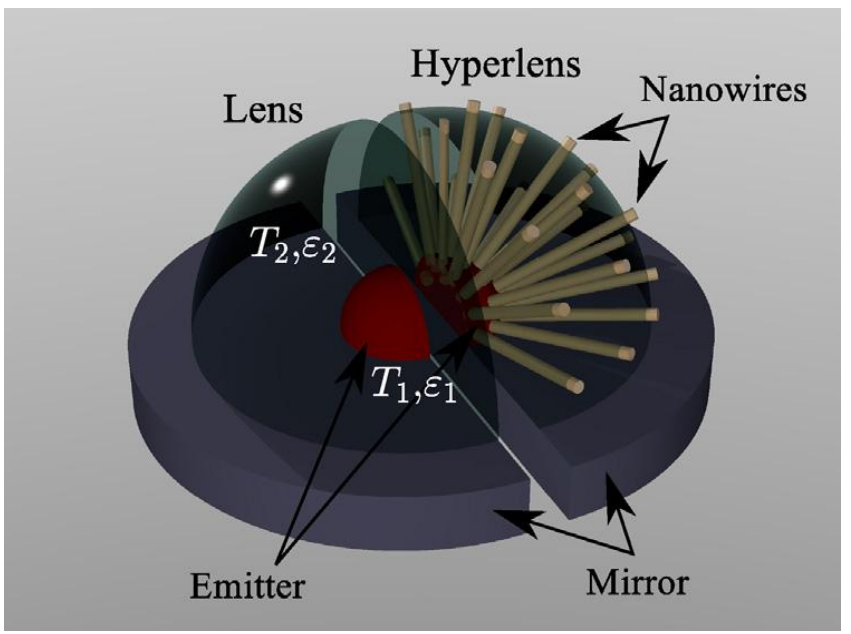

Fig. 7. A hemispherical structure for the super-Planckian thermal radiation from a hot emitter modified by tapered metamaterial [15] 
In [15] such metastructure was suggested to modify the usual lens with the aim to enhance thermal radiation of hot body of infrared frequency range. The principle was that the usual hemispherical lens was filled out by tapered wires and the radiative element (emitter) was located as is shown in Fig. 7. The hyperbolic metamaterial of the hyperlens converts emitter's near fields into propagation modes which effectively radiate from the hyperlens surface.

\section{Tapered Wire Media}

Wire medium can be used for modification of different antennas to radiate evanescent EM waves at the frequencies that do not correspond to the resonance frequencies of modified antenna. Of course, the radiation properties of such modified antennas depend on the features of WM configuration. The work [8] gives an excellent description of this. There, the broadband radiation was the goal of investigation and the irregular metallic structure - WM brush, was suggested based on the properties of parallel and tapered metallic structures. The synthesis from the regular WM structure (superlens) and hyperlens to the brush is presented by Fig. 8 [8]. The superlens (Fig. 8a) can support the narrowband radiation at the Fabri-Perot resonance frequencies (Fig. 8d - red solid plot). At the same time, a hyperlens (Fig. 8b) provides radiation not only at resonances, but also between of them, because values of Parsell factor there are more than 1 (Fig. 8d - green dotted plot). However, the dispersion of Parsell factor is not smooth. Therefore, the irregular WM structure (Fig. 8c) was designed as a combination of regular one and hyperlens. It is because the dimensions are the same with first, but the whole structure is as a volume of a huge number of local hyperlens with different lengths, tilts of angles and locations. It makes an effect of reradiating and as a result the dispersion of Parsell factor is smoothed throughout the investigation frequency range (Fig. 8d - pink dash-dotted plot).

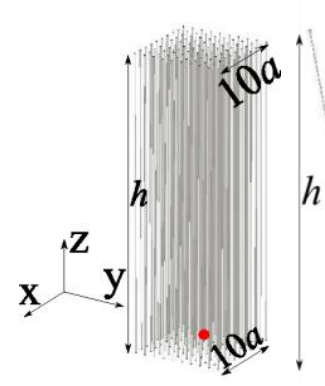

a)

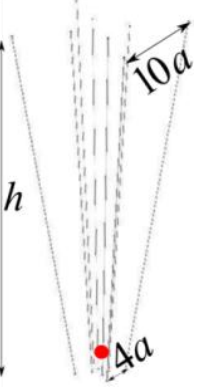

b)

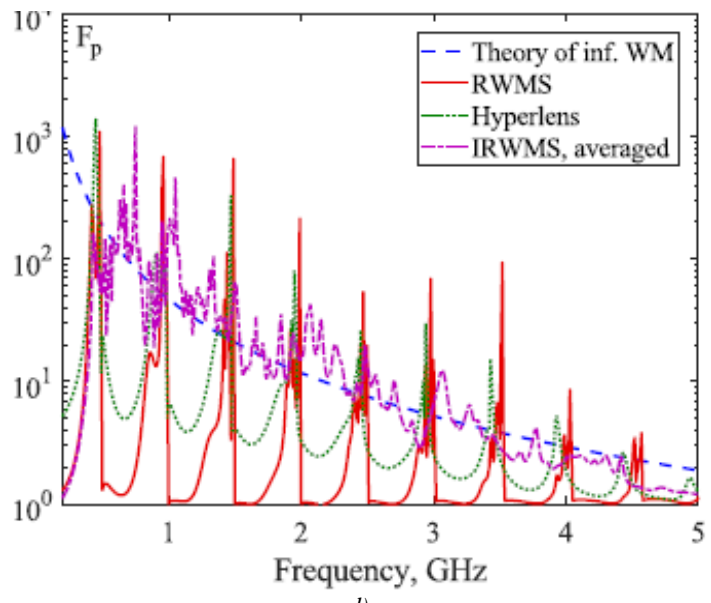

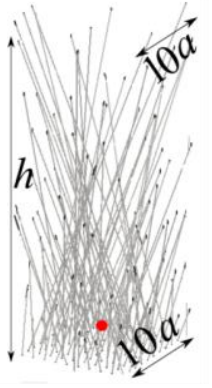

c)
The experimental investigation was performed for previously manufactured samples of parallel and randomized aluminum WM [8]. The external dimensions (length, width and high) of both were the same. The experimental setup that consists of Network Analyzer for displaying of the results, loaded by inductance diaphragm waveguide port and WM sample inserted into the port is shown in Fig. 9a.

In the case when the open waveguide port radiates into the free space without any $\mathrm{WM}$ the values of $\mathrm{S}_{11}$-parameters are approximately equal $-5 \mathrm{~dB}$ (Fig. $9 \mathrm{~b}$ - blue dotted plot). If the waveguide port is modified by regular WM structure the radiation is possible at the resonance frequency (Fig. 9b - black dotted plot). The broadband radiation in the frequency range from 1.1 up to almost $1.4 \mathrm{GHz}$ was achieved with using irregular WM metamaterial (Fig. 9b - red solid plot).

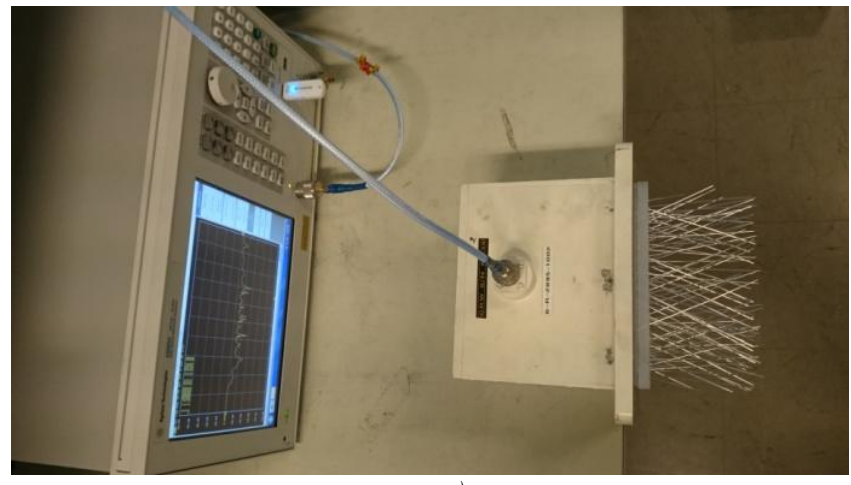

a)

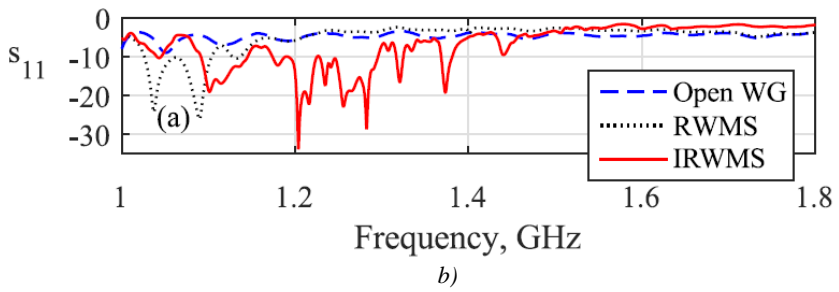

Fig. 9. An experimental setup for the investigation of waveguide port radiation that loaded by irregular WM (a) and $S_{11}$-dispersions when the port radiates into free space (blue dotted plot), through the parallel WM (black dotted plot) and irregular WM (red solid plot) (b) [8]

\section{Conclusions}

The WM metamaterials is a prospective class of unusual materials with unique property (negative value of permittivity) that cannot be found in nature. However, such materials can be synthesized in laboratory. The flexibility of WMs includes the possibility of their manufacturing of different dimensions for the application in very wide frequency range from microwaves up to infrareds [14]. It is possible due to different methods from clearly mechanical to chemical approaches $[2,7,17]$.

The most popular structures are WM that consists of parallel metallic wires, tapered one and with irregular placement of the wires. Each of them possesses the different properties. For example, the first structure is effective for the narrow and broadband power transfer. It has found its application, first of all, for the imaging. Further development and investigation of WM have shown the possibility of using of parallel metallic structures for the sensing, thermophotovoltaic, endoscopy and many others. When the possibility of operation in wide frequency range was proven, the outlook of WM application was changed. The first endoscopes that based on the WM were narrowband [12]. However, the suggested in [20] WM endoscope can operate in wide $\mathrm{THz}$ frequency range that is experimentally proven for microwaves. Moreover, such endoscope is very resistant to the bending with different values of radius including the radius that approximately equal the wavelength.
Fig. 8. A synthesis of wire medium of different shapes from the parallel (a) and tapered $(b)$ ones the irregular structure $(c)$ and the dispersion of Parcell factor when the point electromagnetic wave source is modified by those metamaterials $(d)$ [8] 
The WM with tapered wires shown the possibility to use this class of metamaterials for EM wave radiation. Since the tilt of wires is defined the dispersion of Parcell factor is not smoothed and there are the picks at the resonant frequencies. Therefore, in [8] the new kind of wire metamaterials was proposed, so-called WM brush. The randomized arrangement of wires allows creating a huge number of local hyperlenses with different values of wires, angles and their positions. After such modification the dispersion of Parcell factor became smoothed.

Despite the fact that the metastructure with parallel wires is narrowband it does not mean that this structure is strongly only radiates at resonance frequency. For instance, in [20] was presented the results where the parallel metallic structure can be used for modification of antenna that gives the possibility of radiation in some frequency range. This range, of course, is not very wide, but it is controllable by WM parameters and can find a number of applications in antennas technologies.

The authors believe this paper can expend the horizons in WM development and its applications as well as will be useful for the scientists who work in metamaterial area and find the new engineering solutions for the development for the different radio engineering means.

\section{References}

[1] Albooyeh M.: Electromagnetic Characterization of Metasurfaces. PhD Thesis at Aalto University, 2015.

[2] Atrashchenko A.V., Katz V. N., Ulin V. P., Evtikhiev V. P., Kochereshko V. P. Fabrication and optical properties of porous InP structures. Physica E 44/2012, 1324-1328.

[3] Belov P.A., Marques R., Maslovski S. I., Nefedov I. S., Silverinha M., Simovsk C., Tretyakov S. A.: Strong spatial dispersion in wire media in the very large wavelength limit. Phys. Rev. B. 67/2003, 113103c(1-4).

[4] Belov P.A., Zhao Y., Sudhakaran S., Alomainy A., Hao Y.: Experimental study of the subwavelength imaging by a wire medium slab. Appl. Phys. Lett. 89/2006, 459-462.

[5] Belov P.A., Zhao Y., Tse S., Ikonen P., Silveirinha M. G., Simovski C. R. Tretyakov S. A., Hao Y., Parini C.: Transmission of images with subwavelength resolution to distances of several wavelengths in the microwave range. Phys. Rev. B. 77/2008, 193108 (1-4).

[6] Capolini F.: Theory and Phenomena of Metamaterials. Taylor and Francis Group, LLC, 2009.

[7] Föll H., Leisner M., Cojocaru A., Carstensen J.: Macroporous semiconductors. Materials 3/2010, 3006-3076.

[8] Kosulnikov S. Yu., Mirmoosa M. S., Vovchuk D. A., Tretyakov S. A., Glybovski S. B., Simovski C. R.: Enhancement of Radiation With Irregular Wire Media. IEEE Transactions on Antennas and Propagation 64(12)/2016, 5469-5474.

[9] Kosulnikov S., Filonov D., Glybovski S., Belov P., Tretyakov S., Simovski C. Wire-Medium Hyperlens for Enhancing Radiation From Subwavelength Dipole Sources. IEEE Trans. Antennas Propag. 63/2015, 4848-4856.

[10] Kosulnikov S., Vovchuk D., Nefedov I., Tretyakov S., Simovski C.: Broadband Power Transfer Through a Metallic Wire Medium Slab. URSI International Symposium on Electromagnetic Theory (EMTS), Espoo 2016, 596-599.

[11] Mirmoosa M.S., Simovski C. R.: System Analysis of Micron-Gap Thermophotovoltaic Systems Enhanced by Nanowires. Photonics and Nanistructures - Fundaments and Applications 13/2015, 20-30.

[12] Radu X, Garray D., Craeye C.: Towards a wire medium endoscope for MRI imaging. Metamaterials 3/2009, 90-99.

[13] Sihvola A.: Metamaterials in electromagnetic. Physical Review Letters 85(18)/2000, 3966-3069.
[14] Simovski C., Belov P.A., Atrashchenko A.V., Kivshar Yu. S.: Wire metamaterials: Physics and applications. Advanced Materials 24/2012, 4229-4248.

[15] Simovski C., Maslovski S., Nefedov I., Kosulnikov S., Belov P., Tretyakov S.: Hyperlens makes thermal emission strongly super-Planckian. Photonics and Nanistructures - Fundaments and Applications 13/2015, 31-41.

[16] Simovski C., Vovchuk D., Kosulnikov S. Power Vortices in Wire-Medium Endoscopes (Invited). 12 $2^{\text {th }}$ International Congress Metamaterials, Espoo 2018, 315-317.

[17] Ulin V. P., Konnikov S. G.: Electromechanical pore formation mechanism in III-IV crystals. Semiconductors 41/2007, 832-844.

[18] Vovchuk D., Khobzei M., Zhadan I.: Properties of Antennas Modified by Wire Media. Proceedings of $1^{\text {st }}$ International Conference on Informatioon and Telecommunication Technologies and Radio Electronics (UkrMiCo), Odessa 2018.

[19] Vovchuk D., Kosulnikov S., Nefedov I., Tretyakov S., Simovski C.: MultiMode Broadband Power Transfer through a Wire Medium Slab. Progress In Electromagnetics Research (PIER) 154/2015, 171-180.

[20] Vovchuk D., Kosulnikov S., Simovski C.: Unusual eigenmodes of wire-medium endoscopes: impact on transmission properties. Optics Express 26(14)/2018, 17988-18005.

\section{Mykola Khobzei}

e-mail: hobze7@gmail.com

Bachelor student at Radio Engineering and Information Security Department of Yuriy Fedkovych Chernivtsi National University. Research field includes wire metamaterials for the transmission and radiation. Author of more than 5 publications.

ORCID ID: 0000-0002-9101-8569

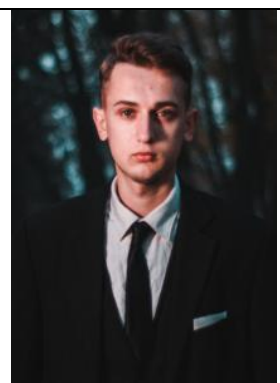

\section{Ph.D. Dmytro Vovchuk}

e-mail:dimavovhuk@gmail.com

Teaching assistant (Ph.D., Candidate of Science) at Radio Engineering and Information Security Department of Yuriy Fedkovych Chernivtsi National University. Research field includes metamaterials for the radio devices applications. Author of more than 10 publications.

ORCID ID: 0000-0001-7108-8984

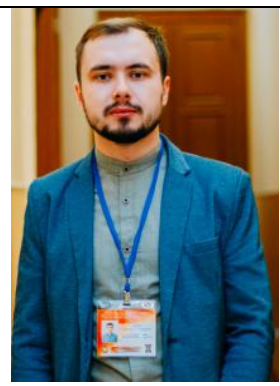

\section{M.Sc. Magdalena Michalska}

e-mail: magdalena.michalska@pollub.edu.pl

$\mathrm{Ph}$.D. student, Institute of Electronics and Information Technology, Lublin University of Technology Recent graduate Warsaw University of Technology The Faculty Electronics and Information Technology. Since 2017Graduate Student Member, IEEE Students or IEEE Graduate Students, Poland Section Branch Lublin University of Technology. Research field covers medical image processing, 3D modelling, optoelectronics, spectrophotometry.

ORCID ID: 0000-0002-0874-3285

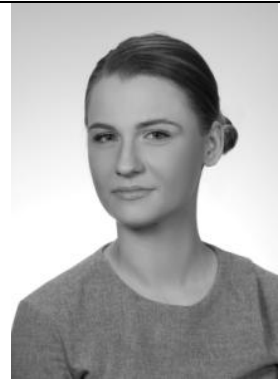

otrzymano/received: 1.10 .2018

przyjęto do druku/accepted: 15.12 .2018 